\title{
Produção de Vida em Tempos de Morte: cinco movimentos esquizoanalíticos ${ }^{1}$
}

\section{Production Of Life In Times Of Death: five schizoanalytic movements}

\author{
DOMENICO UHNG HUR \\ Professor Associado de graduação e pós-graduação em \\ Psicologia da Universidade Federal de Goiás \\ domenicohur@hotmail.com
}

\section{RESUMO}

Vivemos num período marcado pela morte, hostilidade contra às diferenças, autoritarismos explícitos e que em grande parte são difundidos pelo próprio Governo federal. Dessa forma, esse artigo tem como objetivo refletir sobre pistas para a produção de vida em tempos atuais de propagação de morte, tanto no âmbito individual, como coletivo, a partir do referencial teórico da esquizoanálise. O método utilizado foi a seleção de alguns conceitos da filosofia da diferença de Gilles Deleuze e Félix Guattari para operar essa reflexão sobre o contemporâneo. Como resultados discutimos cinco movimentos da esquizoanálise para produção de vida: a transmutação das forças; adotar o próprio território como ponto de partida; trabalhar a potência do occursus; valorizar o infinitamente pequeno; e fomentar o afeto, os devires, como passagem.

Palavras-chave: Esquizoanálise. Esquizodrama. Gilles Deleuze. Félix Guattari. Psicologia. Política.

\begin{abstract}
We are living in a period marked by death, hostility to differences, explicit authoritarianism, which is largely spread by the federal government itself. Thus, this article aims to reflect on clues for the production of life in times of death, based on schizoanalysis. The method used was the selection of some concepts from the philosophy of difference of Gilles Deleuze and Félix Guattari to operate this reflection on the contemporary. As a result, we discuss five schizoanalysis movements for the production of life: the transmutation of forces; adopting the territory itself as a start point; working the power of occursus; to value the infinitely small; and foster affection, becomings, as a passage.
\end{abstract}

Keywords: Schizoanalysis. Schizodrama. Gilles Deleuze. Félix Guattari. Psychology. Politics.

\section{INTRODUÇÃO}

A pandemia do coronavírus, o extermínio da população negra, periférica, dos povos indígenas, o preconceito contra os imigrantes, as práticas do Governo federal, são a

\footnotetext{
${ }^{1}$ Artigo submetido para avaliação em 19 de setembro de 2021 e aprovado em 19 de outubro em 2021.
} 
Rev. Interd. em Cult. e Soc. (RICS), São Luís, v. 7, n. 2, p. 95- 113, jul./dez. 2021

ISSN eletrônico: $2447-6498$

expressão do atual zeitgeist; espírito (geist) da época (zeit). São exercidas as políticas e práticas da morte. Necropolítica total e generalizada, propagada não apenas pelo poder soberano (MBEMBE, 2018), mas produzida predominantemente pela axiomática do capital (DELEUZE; GUATTARI, 1972²). Famílias que de repente perdem um ente querido, indígenas que são expulsos do espaço liso de seus territórios há séculos, o jovem negro que caminha precavido por sua rua na volta do trabalho, temendo uma bala perdida. Todos estamos com a morte à espreita, em que o corpo social mortifica a própria sociedade. Tanatopolítica. Vivemos numa terra arrasada, não desterritorializada. Estamos desterrados. Subtraíram-nos e nos subtraem nossa terra, nossas vidas, constante e fortemente. E nos lamentamos e nos ressentimos.

Dessa forma, esse artigo tem como objetivo refletir sobre pistas para a produção de vida em tempos atuais de propagação de morte, tanto no âmbito individual, como coletivo, a partir do referencial teórico da esquizoanálise. Busca traçar linhas para que possamos escapar das forças reativas, do ressentimento (DELEUZE, 1962), para a produção de novos possíveis. Enfim, refletir como fomentar devires revolucionários, e não focalizar apenas no futuro da revolução (DELEUZE, 2003).

O método utilizado foi a seleção de alguns conceitos da filosofia da diferença de Gilles Deleuze e Félix Guattari para operar essa reflexão sobre o contemporâneo. Buscamos discutir possíveis movimentos para que se abram sendeiros e trilhas que escapem das políticas da morte. $\mathrm{O}$ autor do presente artigo é conhecedor e estudioso de toda obra publicada de Deleuze e Guattari e constantemente publica revisões teóricas sobre a obra da dupla, bem como artigos, capítulos e livros na Psicologia, inspirados e referenciados pela esquizoanálise. Destaca-se que neste artigo foram pinçados somente alguns conceitos, e que obviamente há outros da obra deleuzo-guattariana que podem contribuir para esta reflexão sobre a produção de vida em tempos de morte, e que não foram citados aqui.

Realizamos nossa reflexão de um modo não usual. No primeiro tópico, ao invés de nos "distanciarmos" pessoalmente da temática investigada, nos implicamos ao máximo, em que partimos de nossa própria experiência singular, individual, e a articulamos com o zeitgeist de morte. Partimos de uma leitura do presente a partir de um olhar vibrátil (ROLNIK, 1997), de uma dimensão háptica (DELEUZE, 1981a), na qual o olhar do pesquisador é afetado pelas forças que o envolvem, numa modalidade de um 'olhar tátil' (HUR, 2020a; 2021a).

\footnotetext{
${ }^{2}$ Nas obras de Deleuze e Guattari colocamos a data original da primeira edição de publicação, ou de quando foram proferidos os cursos. Assim o ano de publicação das versões traduzidas apenas aparecem nas referências bibliográficas.
} 
Rev. Interd. em Cult. e Soc. (RICS), São Luís, v. 7, n. 2, p. 95- 113, jul./dez. 2021

ISSN eletrônico: $2447-6498$

Evidentemente, no primeiro tópico, ao se construir uma narrativa a partir de um 'mim', buscase articular a um 'nós', numa ressonância afetiva entre experiência singular e coletiva. No segundo tópico desenvolvemos as pistas em cinco movimentos que podem contribuir para a produção de possíveis, de linhas de fuga que escapem desse diagrama da morte. Nossa referência principal foi a filosofia de Deleuze e Guattari, bem como o Esquizodrama, inventado por Gregorio Baremblitt (1998) e breves citações de teóricos indígenas.

\section{UM ZEITGEIST DA MORTE}

Minha experiência pessoal ${ }^{3}$ acompanha o mesmo zeitgeist de morte atualizado no campo social, mas por outras razões. Não sofro os percalços étnico-raciais e econômicosociais, mesmo ocupando o lugar paradoxal de possuir uma 'carne amarela', e tampouco fui atingido pela infecção viral. Mas por uma translocação cromossômica, uma transmutação molecular, houve uma alteração genética e a medula óssea de minha companheira passou a produzir células blásticas que atacam o próprio organismo, exterminando plaquetas, leucócitos, hemácias. Leucemia linfoide aguda, philadélfia positivo. Uma reação autoimplosiva em que o organismo mortifica o próprio corpo, e que não está localizada apenas num órgão, tecido, ou estrato, mas circula por toda a extensão corporal, navegando por seus fluxos sanguíneos. Não se consegue enfrentá-las numa territorialidade específica, como encerrando as células patógenas dentro dos 'muros de um estabelecimento', tal como a lógica disciplinar do biopoder opera (FOUCAULT, 1975), pois as células cancerígenas estão propagadas no campo aberto de todo o corpo. Não é possível extirpar uma parte do tecido, ou isolá-las. É no próprio sistema hematopoético que as células mortíferas são produzidas. Podese estabelecer o paralelo entre o que ocorre com esse corpo com o fascismo, pois são os próprios agentes celulares dotados de forças reativas e destrutivas que fazem com que o corpo social se mortifique (DELEUZE, 1986a).

A descoberta da leucemia nos deixou desterrados. Fomos arrastados pelo dilúvio da morte, $40 \%$ de chance de sobrevivência nos próximos cinco anos. Fomos atingidos pela queda do céu que nos fala Davi Kopenawa (2015). Vislumbramos o fim do mundo, o fim dos nossos mundos, como nos alerta Ailton Krenak (2019) e inúmeros outros sábios indígenas. A morte e a terra arrasada nos foram apresentadas de modo a-paralelo. Origens distintas das causas da morte, diferentes forças, mas decorre-se o mesmo afeto (DELEUZE, 1981b),

\footnotetext{
${ }^{3}$ Por este tópico tratar de uma experiência pessoal, singular, adotamos a narrativa na primeira pessoa do singular.
} 
Rev. Interd. em Cult. e Soc. (RICS), São Luís, v. 7, n. 2, p. 95- 113, jul./dez. 2021

ISSN eletrônico: $2447-6498$

atualizado no âmbito individual e coletivo. Resulta-se assim um afeto de tristeza, de impotência, que subtrai a potência do corpo individual e social (DELEUZE, 1981c).

E o tratamento da leucemia consegue ser ainda mais mortífero que a própria doença. A quimioterapia é tão forte que queima todos tecidos. Para eliminar as células cancerígenas, também elimina intensamente as células sanguíneas 'saudáveis': glóbulos vermelhos, glóbulos brancos, plaquetas; tudo é destruído. Os 'mecanismos de segurança', 'biopolíticos' (FOUCAULT, 1999) de combate ao agente infeccioso, utilizam a tática da terra arrasada. Como a guerra ocorre em todo campo aberto do espaço corporal, para eliminar as células cancerígenas, o que resta de corpo 'sadio' também deve sofrer essa depuração e abolição. Decorre-se assim um paradigma imunitário (DELEUZE, 1986a), em que há uma destruição quase total para garantir a vida do corpo.

Contudo, mesmo com a estratégia de terra arrasada, não há cura por medicação, por quimioterápico algum. Devido a ser philadélfia positivo, pode-se atingir a 'cura' apenas por transdução do sistema hematopoético de um ser externo: transplante de medula óssea. Isto é, deve haver a migração de um sistema de criação de novas células, moléculas, novos povos, que possam habitar esse corpo, essa terra recém-arrasada, o deserto, produzindo um novo mundo, um novo sistema e circuito desejante. Uma nova ocupação e territorialização de populações de células criadoras, que germinem um novo corpo, um novo mundo e um novo viver.

Mas que novas vidas produzir? No nosso caso, não poderemos ter filhos, não reproduziremos o tradicional e 'normativo' modelo familiar arborescente. Futuramente não ocuparemos nossas preocupações com a educação de filhos, que a cada dia ficam mais 'mimados'. E também há uma redução da potência motora corporal. Não lograremos mais realizar feitos físicos e esportivos, como correr uma maratona de quarenta e dois quilômetros. Portanto, não poderemos seguir o imperativo neoliberal, da axiomática do capital e do corpocapital (HUR, 2015; 2018), de sempre acelerar a produtividade do objeto qualquer (DELEUZE, 1979), em que o corpo máquina deve se hipertrofiar e produzir o máximo possível.

Enfim, com a morte e a queda à espreita, o que fazer? Negar a realidade e praguejar? Aceitar a fatalidade e chorar? Odiar e deplorar o outro e a diferença? Estamos desterrados, com a sombra da morte, e sem modelos pressupostos a seguir. Não há ideais transcendentes a se ancorar, nem a esperança do poder do Estado a se tomar, mas a floresta da imanência a se navegar. Como Krenak (2019) nos ensina, para desacelerar a queda, devemos abrir paraquedas, os mais coloridos possíveis, para produzir desvios e outras possibilidades. 
Rev. Interd. em Cult. e Soc. (RICS), São Luís, v. 7, n. 2, p. 95- 113, jul./dez. 2021

ISSN eletrônico: $2447-6498$

Novas trajetórias, relações diferenciais, desvios: clinamen! (DELEUZE, 1969; BAREMBLITT, 2019). Possivelmente o pensamento de Krenak esteja mais próximo da esquizoanálise do que imaginávamos, mesmo que ambos tenham tido uma gênese conceitualgeográfica bastante distante. E como Casé Angatu também nos inspira, podemos ter levado cinco séculos de porrada, mas continuamos lutando, rindo, 'colocando o inimigo no cipó'. As forças ativas devem irromper de toda a reatividade e niilismo em que vivemos, por mais que morramos. Todos morreremos. Mas aqui não é uma ação para a morte, de termos um tempo finito e limitado, tal como uma perspectiva heideggeriana (HEIDEGGER, 1995). Pelo contrário, é uma ação para a vida, para a produção de outras vidas, intensivas e infinitas, mesmo com as fronteiras de suas limitações.

Devemos assim criar nossas próprias linhas, acreditar na nossa própria potência e insistir e reexistir na vida (FUMIATO; SANTA CRUZ, 2005). Mesmo com a terra arrasada, temos um corpo, e que devemos ao máximo cartografá-lo, senti-lo, experimentá-lo, por mais que em muitos casos ainda desconheçamos sua potência (DELEUZE, 1981c).

\section{CINCO MOVIMENTOS PARA A PRODUÇÃO DE SENDEIROS EM TEMPOS DE MORTE}

Para criar linhas de fuga frente às políticas e práticas da morte, deve-se adotar algumas pistas para a abertura de novos sendeiros. Do manancial de conceitos, concepções e dispositivos que nos proporciona a esquizoanálise, derivamos cinco movimentos. Cinco pistas, que nesse caso, não são descartáveis, mas imprescindíveis para a produção de novas configurações de forças e um outro viver nesse tempo marcado pelo zeitgeist da morte. Como supracitado, poderiam ser trabalhados inúmeros outros conceitos, outros processos. Contudo, através de nossa cartografia (DELEUZE; GUATTARI, 1980a; ROLNIK, 1989) situada histórico-geograficamente, mediada por nosso olhar háptico (DELEUZE, 1981a), seguimos esses cinco afluentes, como meios para pensar a produção de outras modalidades de vida, outras subjetivações, e não reproduzir as forças hegemônicas políticas, que disseminam ressentimento e o niilismo generalizado. São eles: a transmutação das forças; adotar o próprio território como ponto de partida; trabalhar a potência do occursus; valorizar o infinitamente pequeno; e fomentar o afeto, os devires, como passagem. Eles são apresentados não no ponto de vista evolucionista, em que um passo levaria a outro. Não necessariamente há uma ordem a seguir, pode-se trabalhar qualquer um deles, iniciar por qualquer um, trafegá-los ao mesmo tempo, sem uma ordenação determinante. 
Rev. Interd. em Cult. e Soc. (RICS), São Luís, v. 7, n. 2, p. 95- 113, jul./dez. 2021

ISSN eletrônico: $2447-6498$

Esses cinco movimentos são as máquinas centrais deste texto-dispositivo, inspirado e fundamentado pela filosofia de Deleuze e Guattari (1980a), na qual buscamos a potência de suas concepções para lidar com os desafios que enfrentamos na atualidade. É um artigo-rizoma que tenta migrar sua potência filosófica como armas de combate para continuarmos prosseguindo e produzindo uma vida não marcada pelo ressentimento e forças reativas. De tal forma que consideramos que esses movimentos podem ser adotados na klínica ${ }^{4}$ esquizoanalítica, por ativistas em movimentos sociais, como também por indivíduos e coletivos interessados na produção de um outro viver, alternativo ao zeitgeist da morte.

\section{$1^{\circ}$ - Transmutação das forças}

Vivemos num período marcado pela morte, hostilidade contra às diferenças, autoritarismos explícitos e uma grande difusão de um tipo de discurso-prática denominado como bolsonarismo. E tal configuração de forças inclusive está incorporado no Estado, atualizando ao máximo o que Foucault (1999) denomina como Estado racista. Em todos estes contextos se pregam o ódio, a deploração do outro e um não cuidado com a vida. Tal como Deleuze (1962) afirmaria, esses processos são os sintomas de uma determinada modalidade de forças, são a expressão e atualização do niilismo, a cristalização e triunfo das forças reativas e da vontade do nada.

Deve haver assim um novo movimento que não reproduza essa reatividade, por mais que seja árduo e difícil. Como não se entristecer e não reagir reativamente ao estado de coisas em que vivemos? Como não odiar a quem nos odeia? Se respiramos a morte, como transpirar vida? Então, um movimento fundamental deve ser a efetuação de uma torção das forças, a sua dobra (DELEUZE, 1986b).

Independente de qual dispositivo (DELEUZE, 1989; HUR, 2012) se adote, devemos buscar a realização dessa dobra, uma flexão da força, que resulte na transmutação das forças reativas às ativas (DELEUZE, 1962). Nessa torção das forças, fomenta-se que o niilismo experienciado dê lugar à produção desejante de vida. A negatividade do egoísmo, a antipatia, dê espaço à associatividade da simpatia (DELEUZE, 1953) e ao altruísmo. Resultando numa rotação em que o ressentimento e o ódio sejam expulsos pelo dispositivo do

\footnotetext{
4 Gregorio Baremblitt (1998) grafa klínica com ' $k$ ' e não com 'c' para diferenciar sua prática da clínica tradicional. Na clínica, etimologicamente, há o movimento do agente de saúde debruçar-se sobre o enfermo. Já na klínica, inspirado pela ideia de clinamen, busca produzir desvios, diferenças e acontecimentos a partir desse encontro.
} 
Rev. Interd. em Cult. e Soc. (RICS), São Luís, v. 7, n. 2, p. 95- 113, jul./dez. 2021

ISSN eletrônico: $2447-6498$

eterno retorno (DELEUZE, 1962), num movimento centrífugo que expulse as forças reativas e de morte, para que retornem apenas as forças da vida, que insistem e que constroem.

No campo da clínica esquizodramática, constatamos que essa transmutação das forças também produz uma transição dos modos afetivos, tal como Espinosa teoriza (DELEUZE, 1981c). Há uma dobra afetiva que pode levar a transição da tristeza à alegria. Por isso Baremblitt (1998) aposta em novos dispositivos, seja no campo da klínica, na arte e nos movimentos sociais, para a produção dessa nova qualidade de forças. E assim criar novos agenciamentos, aparelhagens, máquinas. Linhas de fuga e máquinas de guerra desejantes (DELEUZE; GUATTARI, 1980c) em seus diferentes contextos de atuação para a atualização de um devir-revolucionário e, quem sabe, até na construção de um futuro da revolução.

\section{$2^{o}$ - Adoção do território como ponto de partida}

A esquizoanálise exalta a produção de rizomas e a constituição de territórios existenciais singulares (DELEUZE; GUATTARI, 1980a; GUATTARI, 1989). Contudo, o intelectual das ciências humanas brasileiras está mais próximo de Sorbonne, do que do Capão Redondo (SP), Rocinha (RJ), ou do Setor Garavelo (GO). Sonha mais com Paris e Londres, do que com a Amazônia. Mesmo que conheça suas situações materiais e sociais, tais conteúdos não costumam aparecer em suas reflexões e publicações. Não é à toa que Foucault denominou o departamento de Filosofia da antiga Faculdade de Filosofia, Ciências e Letras da Universidade de São Paulo (FFCL-USP) de departamento francês de ultramar (RODRIGUES, 2016), ou Lévi-Strauss se surpreendeu com a biblioteca de intelectuais brasileiros, que se assemelhavam às bibliotecas de intelectuais franceses.

Entretanto, não nos basta importar os conhecimentos filosóficos produzidos na Europa e 'aplicá-los' aqui sem uma modulação geográfica-histórica. De certa forma, muitas vezes as ciências humanas se europeízam no Brasil e se esquecem de seu próprio contexto, como o que ocorreu com a psicanálise lacaniana mainstream no país. Assim, a esquizoanálise deve germinar e se alastrar em território brasileiro com todo o seu caráter híbrido, mesclado, e combater os desafios vigentes, que atualmente é a luta contra as forças reativas e de morte, que são amplificadas por um extremismo político de direita.

Tomemos um exemplo de um agenciamento singular que constitui uma esquizoanálise latino-americana: o esquizodrama. Compreendemos que a esquizoanálise primeiramente é uma Filosofia. Mas no Brasil e na América do Sul houve uma migração desse conteúdo filosófico para o campo da clínica, bem como para outros, como as artes, a 
Rev. Interd. em Cult. e Soc. (RICS), São Luís, v. 7, n. 2, p. 95- 113, jul./dez. 2021

ISSN eletrônico: $2447-6498$

política, a educação etc. Uma das criações mais insólitas dessa transdução filosófico-clínica é o esquizodrama, criado por Gregorio Baremblitt na década de 1970 (HUR, 2014; BAREMBLITT, 2021). Vale também destacar que o esquizodrama não é mera aplicação da esquizoanálise, pois com a performatização de seus conceitos em inúmeros dispositivos há uma profícua produção de outros conceitos e concepções (BAREMBLITT, 1998; 2019; BAREMBLITT, AMORIM, HUR, 2020b).

O esquizodrama instaura um choque de materialidades, um turbilhão que produz uma fenda, uma rachadura, que faz escorrer fluxos de possíveis. Ele porta novos enquadramentos clínicos, não utiliza apenas o consultório privado tradicional. Não é fechado entre quatro paredes, não é uma clínica stricto sensu. Ele é operado com o passeio do esquizo (DELEUZE; GUATTARI, 1972), podendo ser realizado no campo aberto, nas praças, nos Centros de Atenção Psicossocial (CAPS) de saúde mental, nas ocupações estudantis (HUR; COUTO, 2019). Se a esquizoanálise tem uma origem europeia, o esquizodrama é latinoamericano. Se Deleuze e Guattari têm Nietzsche, Bergson, Espinosa, Marx etc. como referências, o esquizodrama de Baremblitt tem também os saberes populares dos povos autóctones e dos movimentos sociais como inspiração, ou ao menos tenta aprender com eles. Pois aqui não estamos somente ocupados pelos franceses da Champs Élysées do maio de 68, mas também pelos xapiris, orixás e encantados do solo brasileiro. Se a esquizoanálise se desenvolveu em Vincennes, ou nos cafés e bibliotecas parisienses, o esquizodrama surge nos sótãos, cheios de almofadas (da Rua $\operatorname{Herval}^{5}$ ), nas performances em porões cheios de gente em Belém do Pará (LIMA, 2014), nos CAPS, como o Maria Boneca (BICHUETTI, 1999; 2000), nas praças públicas e quem sabe futuramente nas periferias, nas encruzilhadas, terreiros e giras.

O esquizodrama é uma klínica das forças e, portanto, deve apreender também as forças das lutas dos movimentos sociais brasileiros. O Movimento dos Trabalhadores Sem Terra (MST), os movimentos indígenas, todas as minorias exploradas e não escutadas, mas que têm muita potência e conteúdo a dizer e nos ensinar, sempre inspiram e potencializam o esquizodrama. Assim, não devemos esquecer do potencial revolucionário de nosso território latino-americano. De forma contrária do que preconizam as bíblias marxistas e seus profetas, a primeira revolução proletária não começa na Europa, não foi a Revolução comunista, nem a Comuna de Paris. A primeira revolução proletária que inclusive é racial e antirracista tem lugar na América Latina, mais precisamente no Haiti (1791-1804). Assim, “[...] a primeira

\footnotetext{
${ }^{5}$ Rua em que está sediada o Instituto Gregorio Baremblitt. É no sótão onde são ministradas a formação e klínicas de esquizodrama.
} 
Rev. Interd. em Cult. e Soc. (RICS), São Luís, v. 7, n. 2, p. 95- 113, jul./dez. 2021

ISSN eletrônico: $2447-6498$

revolução proletária vitoriosa foi feita por escravizados [...]”" (ALLIEZ; LAZZARATO, 2021, p. 108). "Muito antes do Exército vermelho soviético ou do exército da China, o exército negro é a primeira força proletária a revolucionar profundamente a arte da guerra [...]" (ALLIEZ; LAZZARATO, 2021, p. 109). E produzem uma revolução em que não importam meramente os modelos militaristas europeus de exército, mas os conjugam a táticas guerrilheiras moleculares e rituais de vudu. C. L. R. James narra esse bonito sincretismo entre organização militar e rituais religiosos do território: "Utilizando tochas para indicar o caminho, os líderes da revolta se reuniam em um espaço aberto da espessa floresta de Mourne-Rouge, uma montanha avultando-se sobre Cap François, a maior cidade. Assim, Boukman (apud ALLIEZ; LAZZARATO, 2021, p. 109), ''[...] o chefe, depois de fazer feitiços de vudu e beber o sangue de um porco, deu as últimas instruções ${ }^{6}[\ldots]$ ”.

Pois tal como a guerrilha colombiana M-19 afirmava, aqui não é a União Soviética, mas sim Macondo. E se formos um dia fazer a revolução, será bailando cumbia, com maracas. Ou então, aqui no Brasil, dependendo da geração etária, cantando um samba, batendo a cabeça com rock, ou dançando funk. Então nossas referências não devem ser apenas Lenin e Rosa Luxemburgo, mas Marighella, Marielle e Iara Iavelberg.

Nesse sentido, devemos produzir conhecimentos, e vida, em diversos espaços. Não apenas sacralizar o altar da Igreja-Universidade, mas transitar pela cidade em suas diferentes zonas de intensidade. Não apenas reproduzir pesquisas e estudos para as elites, mas constituir também, de modos alternativos, uma Psicologia favelada (GONÇALVES, 2019). Agenciar tais dispositivos teóricos e técnicos, potentíssimos, ao nosso contexto e realidades, numa experimentação nomádica em que colheremos seus resultados e ramificações. E obviamente, não ignorando nossa própria territorialidade de origem, por mais que tenham sido terras abandonadas, mas que ainda carregamos em nós, bem como as margens que trafegamos e as dissidências que provocamos.

\section{$3^{\circ}$ - Potência do Occursus}

Outro movimento fundamental para ultrapassar o atual estado de coisas é acreditar na potência do que Espinosa denomina de Occursus, ou seja, do encontro (DELEUZE, 1981b), seja na clínica, nos movimentos sociais, na vida. Os encontros sempre trazem a variação da potência, a transição de afecções. Então não devemos buscar apenas os encontros,

\footnotetext{
${ }^{6}$ JAMES, C. L. R. A History of Pan-African revolt [1938/1969]. Oakland: PM Press, 2012. p. 40.
} 
Rev. Interd. em Cult. e Soc. (RICS), São Luís, v. 7, n. 2, p. 95- 113, jul./dez. 2021

ISSN eletrônico: $2447-6498$

mas sim, neles, buscar as relações de composição de forças que formam e resultam de agenciamentos e máquinas concretas. Mas como criar agenciamentos e composições com outros? Como captar a irrupção e potencialização das forças nos encontros?

Espinosa busca discutir o que pode um corpo, a potência de um corpo, a partir de seus movimentos e composições. Para tanto, visa sair do primado da consciência e apreender as relações de afecções entre os corpos. Nessas composições há relações de afetar e ser afetado pelo(s) outro(s) corpo(s), nas quais as distintas combinações podem aumentar, ou diminuir, os graus de potência de um corpo. Dessa forma se há uma combinação entre as forças e afetos de corpos distintos, resulta-se um processo de composição que leva a uma potencialização de ambos os corpos, resultando um bom encontro. De modo contrário, se a relação com um corpo envenena o meu, o subtrai de suas próprias forças, há uma relação de decomposição característica de um mau encontro (DELEUZE, 1981c). Portanto, nos regimes de composição estão associados afetos de produção da vida, como a alegria, a fruição, enquanto nas relações de decomposição, afetos de subtração da potência da vida, como a tristeza e o ressentimento. Deste modo, os afetos resultam de processos relacionais e de encontros entre corpos, mas não apenas de humanos, como também entre humano e inumano. Há uma composição de (des)potencialização entre corpos de materialidades heterogêneas que produzem acontecimentos e estados afetivos (HUR, 2016).

Dessa forma, devemos cartografar o corpo, as conexões, e buscar as forças onde achamos que só há fraqueza. Compor e não decompor relações. Adicionar e não subtrair. Tomar as forças e produzir vida em suas diversas faces. Saltar os bloqueios do 'muro branco'. Parir e gestar novos mundos. Pois a conexão e agenciamentos que fazemos com outros corpos podem amplificar nossa potência.

Na composição das relações de forças, formamos novos circuitos desejantes, mais potentes, capazes das mais insólitas realizações (DELEUZE; GUATTARI, 1975; HUR, 2020b). Por isso, nesse mundo desterrado, para lograr a manutenção da vida, devemos aumentar a conexão, encontros e fusão com outros corpos. No exemplo do tratamento da leucemia, uma forma de garantir a vida é a trans-fusão de hemácias e plaquetas. É produzida uma conexão de fluxos sanguíneos com uma população de anônimos, mistura de fluxos, num diagrama distinto dos atuais vigentes. Ao invés de um diagrama disciplinar (FOUCAULT, 1975), de controle (DELEUZE, 1990), ou de um capitalismo extremista, que configura o necroliberalismo bolsonarista (HUR, no prelo), a produção da vida se ampara numa espécie de diagrama do cuidado e da solidariedade, ou melhor, num diagrama da ecosofia (GUATTARI, 1989; 2015). Deve haver uma migração celular entre corpos, numa terapêutica 
Rev. Interd. em Cult. e Soc. (RICS), São Luís, v. 7, n. 2, p. 95- 113, jul./dez. 2021

ISSN eletrônico: $2447-6498$

que se baseia na desterritorialização e circulação, numa autêntica produção de um Corpo sem Órgãos (DELEUZE; GUATTARI, 1980b), com toda sua crueldade e sofrimento. Na hemoterapia, a raspagem e a demolição são realizadas pela quimioterapia, enquanto a circulação de novos fluxos é proporcionada pela trans-fusão e pela futura atividade criadora do sistema hematopoético em reconstituição. É curioso que podemos afirmar que a hemoterapia é uma esquizoanálise em ação, e nos arriscamos a dizer que é a disciplina médica $^{7}$ mais esquizoanalítica, e não a psiquiatria.

Deve-se operar nos occursus uma trans-fusão, não apenas de sangue, mas de sonhos, afetos, intensidades, projetos, realizações, que podem levar nossos corpos a dimensões antes não imaginadas. $\mathrm{O}$ corpo isolado tende a uma reatividade, mas o corpo em composição a atividades insólitas, a um agenciamento de máquina de guerra desejante, que devém os possíveis em realidades. A produção de novas vazões desejantes que aspiram não a constituição de normas, da arborescente família nuclear burguesa, da reprodução do falacioso modelo do empreendedor, atualizado pela axiomática do capital (DELEUZE; GUATTARI, 1972), ou de todos os ideiais da transcendência. A potência do occursus nos possibilita escapar dessas ficções para criar afecções, novas produções simbólicas e afetos. O que é um grande desafio. $\mathrm{O}$ encontro deve ser capaz de produzir potências e não poder. Pois o poder é a força domesticada (MASSUMI, 1992), ou melhor, o poder é a potência apodrecida, morta (BAREMBLITT, 1998).

\section{$4^{o}$ - Valorização do infinitamente pequeno}

Não devemos apreender apenas a transformação macropolítica, o resultado final da ação, mas também valorizar o infinitamente pequeno (DELEUZE, 1968; 1981b). Devemos abandonar o movimento da transcendência, de perseguir os ideais e utopias inatingíveis, tal como mudanças macropolíticas que vão muito além de nosso potencial de ação. Por exemplo, se temos um Governo federal que nos entristece, nos aborrece e que produz a disseminação dos discursos de ódio e também uma ampliação das políticas de morte, não devemos nos sentir deprimidos se nós, em nossa ação política, não conseguimos retirá-lo e produzir outro governo. Pois o Estado é uma máquina concreta que se refere a uma população de cerca de

\footnotetext{
${ }^{7}$ Outro debate importante é refletir sobre os distintos diagramas de forças atualizados pela Instituição médica e seus agentes. Evidentemente pode-se constatar a atualização de um diagrama disciplinar de modo muito intenso, mas também, em alguns agentes, minoritários, o diagrama da ecosofia, ou de um cuidado, aludido.
} 
Rev. Interd. em Cult. e Soc. (RICS), São Luís, v. 7, n. 2, p. 95- 113, jul./dez. 2021

ISSN eletrônico: $2447-6498$

211 milhões de pessoas, numa dimensão macropolítica que supera em muito nosso escopo de ação ${ }^{8}$.

Devemos abandonar o ideal da transcendência, as imagens de pensamento instituídas e trafegar na lógica da imanência, valorizando as transformações do infinitamente pequeno. Para Deleuze $(1968 ; 1981 b)$ o infinitamente pequeno não é o que tem pouco valor, mas é o que remete às relações diferenciais e à variação dos graus de potência. Assim temos que focar as forças, os graus de potência, que apenas podem ser apreendidos nas relações e nas diferenças que produzem. Investigar os vetores, as velocidades e lentidões dos processos em jogo. Deve haver uma atenção à molecularidade em que se produz conexões e vibrações, trocando a apreensão da igualdade e da estabilidade, para a diferença e a variação contínua. E dessa forma nos enxergar não mais como pontos estanques, mas como devires em movimento. E reconhecer assim que nós somos graus de potência em variação contínua, que produzem diferenças a todo momento. Cada expressão de forças ativas, de fluxos desejantes, já é uma vitória, num momento em que a governamentalidade atual prega o contrário: tristeza, medo e impotência.

Dessa forma não devemos nos autoculpabilizar se nossa ação política, ou ação no mundo, não conseguiu salvar as mulheres do golpe de Estado do Talibã no Afeganistão. Mas sim devemos valorizar o que conseguimos alterar nas relações de poder entre sexo-gênero em nossa esfera imediata, em nossa comunidade. Como conseguimos desconstruir e raspar o machismo cotidiano que reproduzimos, seja em nosso pequeno círculo social, bem como em nós mesmos. Raspar o Talibã do casal, do círculo de amigos, quem sabe até da vizinhança, bem como demolir o Talibã interno. Conseguir desconstruir nossos próprios microfascismos, resultando em pequenas transformações, em linhas de fuga, que conformem clareiras para uma nova suavidade, um novo mundo, mas sem se fixar na preocupação com o futuro da revolução. Cada dia em si já é um combate e uma infinitude, não importando se morreremos amanhã ou daqui cinquenta anos.

Para tanto, não basta viver num movimento social, ou nos denominar como esquizoanalistas, como também temos que produzir movimentos, ou melhor, passagens, trilhas, clareiras, que remetam não apenas à ultrapassagem de determinado problema social enfrentado, bem como um próprio transpassamento de si. Em pontas de desterritorialização que brotem da própria superfície, por mais pequenas que sejam, mas que possam ser

\footnotetext{
${ }^{8}$ A não ser se estejamos à frente de um grande conglomerado financeiro, de setor significativo das forças armadas, de um importante grupo de meios de comunicação, ou de uma Instituição religiosa com milhões de fiéis.
} 
Rev. Interd. em Cult. e Soc. (RICS), São Luís, v. 7, n. 2, p. 95- 113, jul./dez. 2021

ISSN eletrônico: 2447-6498

perceptíveis pelas relações diferenciais que instauram. Afirmar-nos enquanto minorias, expressando suas potências intensivas.

\section{$5^{\circ}$ - O afeto como passagem}

Na esquizoanálise há uma dupla temporalidade expressa por Cronos e Aion. Isso faz com que no setting klínico do esquizodrama haja a atualização de uma métrica e temporalidade singulares. Sua partitura não é redigida por compassos definidos (simples, binários, terciários, quaternários), nem determinada pela duração cronológica de cinquenta ou trinta minutos de uma consulta psicológica padrão. Sua duração não é extensiva, cronológica, mas intensiva, aiônica. Por isso Cronos perde sua determinância, abrindo para o turbilhão, ou mesmo, ao abismo, do caos. Então há o primado da temporalidade que Bergson denomina de duração (DELEUZE, 1966).

No 'bergsonismo' a duração é vista como a temporalidade que produz um bloco de intensidades e de coexistência entre os distintos planos temporais (DELEUZE, 1966). Mas também é o fenômeno de ligação entre dois estados, duas afecções: a passagem de uma afecção à outra. É a transição vivida, ao mesmo tempo corte e ligação, isto é, o puro afeto (DELEUZE, 1981b). Nesse sentido, o movimento da duração implica o próprio afeto, que produz a passagem, um sendeiro para um outro estado. Então são os afetos que passam, produzem bifurcações e linhas. $\mathrm{O}$ afeto é que provoca o movimento, a passagem, realizando a conexão entre dois estados de coisas (DELEUZE, 1981b). Em sua atualização, que remete a passagem de forças, a vazão do desejo, resulta numa instância intermediária, entre.

Nesse sentido, o afeto como passagem não implica apenas numa sucessão temporal entre estados de um mesmo corpo e também não é apenas interno a um ser. Muito longe de se restringir a uma internalidade, ou à lógica do privado, é o que mais é compartilhado numa relação entre-dois, num grupo, ou numa coletividade mais ampla. Sua irrupção está relacionada à atualização de devires, um fluxo entre, que provoca uma brecha no ser para outras configurações, promovendo uma ligação entre distintos corpos.

É como se o afeto fosse uma 'onda' que sintonizasse diferentes corpos numa mesma frequência. É a constituição de um bloco de intensidades, que cria um regime de ressonância em comum e passagem entre ambos. Nesse sentido está no liame entre internalidade e externalidade, individualidade e coletividade.

Este lugar que ocupa, de sintonização e ressonância entre os diferentes corpos, pode gerar os supracitados processos de composição e decomposição das relações. Toda 
Rev. Interd. em Cult. e Soc. (RICS), São Luís, v. 7, n. 2, p. 95- 113, jul./dez. 2021

ISSN eletrônico: $2447-6498$

passagem, todo movimento, implica uma elevação ou "diminuição da potência" (DELEUZE, 1981b, p. 170). Assim ocupa um papel fundamental para a produção e gestão da vida, na qual o Estado o utiliza de forma explícita para gerar relações de dominação e subjugação, mas no nosso caso, perseguimos como a passagem para a produção de vida e de autonomia.

O manejo dos afetos como passagem pode decorrer na produção de distintas afecções, como regimes de forças. Então, por exemplo, no âmbito da klínica, uma interpretação que tenta fazer a passagem, mas decompõe a pessoa, irá produzir tristeza. Da mesma forma que uma experiência autoritária num movimento social também pode trazer essa despotencialização e afeto de subtração decorrente.

Por outro lado, em tempos de extremismos estamos fechados aos afetos como passagem. Estamos cerrados às diferenças. Para não aceder à diferença, uma pessoa pode se fechar ou mesmo chegar a odiar o outro. Para tentar evitar o contato com a diferença, há a produção de "uma quantidade de potência imobilizada" (DELEUZE, 1981b, p. 177). Dessa forma, para tentar impedir aquilo que poderia lhe decompor, ela se 'encouraça', fecha-se. Mas com essa couraça, essa defesa rígida, dificultam-se as passagens, e assim consequentemente a potência do corpo diminui. De tal forma que Deleuze (1981b, p. 174) afirma que "[...] odiar é querer destruir o que ameaça nos destruir [...]”. O ódio acaba sendo uma expressão de tentativa de conservação, de resistência à mudança. Assim, a despotencialização, a tristeza, está na base do ódio. Por isso que também há as alegrias do ódio, uma deploração do outro, que são uma espécie de alegrias de compensação, que seguem as mesmas forças reativas e de um enclausuramento às mudanças e passagens.

Portanto a klínica esquizoanalítica, o esquizodrama, ou o movimento social, não pode apenas desterritorializar, desconstruir, os processos. Para a produção de vida deve apreender como se dá essa dimensão entre, o que a ocupa, o que produz as travessias e passagens. Deve fazer passagens trafegáveis e não jogar as pessoas imprudentemente ao abismo; senão elas se fecham e se encouraçam. Deve produzir o afeto como passagem, como transição, para novas afecções, para a variação do grau intensivo, compreendendo-os como resultantes da vazão do desejo, das forças. Enfim, operar nessa temporalidade singular que se propaga nas passagens da duração e seus regimes de forças resultantes, constituindo novas conexões e composições, para a produção de novos comuns. 
Rev. Interd. em Cult. e Soc. (RICS), São Luís, v. 7, n. 2, p. 95- 113, jul./dez. 2021

ISSN eletrônico: 2447-6498

\section{CONSIDERAÇÕES FINAIS}

Nesse artigo desenvolvemos cinco movimentos, selecionados a partir de uma revisão da literatura esquizoanalítica, que podem nos municiar na luta para a produção de vida em tempos de morte. Atualmente há um diagrama de morte que se atualiza em distintos espaços, como no Governo federal, com a pandemia e no coletivo de forma geral. Desse modo, nossa preocupação se ancora na utopia ativa de conseguir produzir vida em tempos tão difíceis.

Da longa obra esquizoanalítica pinçamos pistas e não ideais, ou teleologias. As pistas-movimentos se referem a práticas que podem ser atualizadas tanto no plano individual, como coletivo. Para essa reflexão também realizamos um diálogo com o esquizodrama, campo teórico-klínico criado por Gregorio Baremblitt.

Nossa reflexão inspirada pela esquizoanálise propõe que para a produção de vida temos que atingir a molecularidade do ser para provocar uma torção das forças, a sua dobra. A finalidade é expulsar sua reatividade e que as forças retornem apenas imbuídas de suas características afirmativas; enfim realizar uma transmutação das forças. Constituir um plano, agenciar processos, não somente com estrangeirismos e elitismo internacional, mas sobretudo reconhecer, mesclar, partir e construir o próprio território. Devemos atuar através de relações diferenciais, abandonando a lógica da transcendência e trafegar no plano da imanência, considerando-nos como graus de potência em variação contínua, ou seja, cartografar e valorizar o infinitamente pequeno, propagar os devires revolucionários e não se angustiar apenas com o futuro da Revolução. Apreender e acompanhar a vazão do desejo, das forças. Eliciar os devires e compreender assim o afeto como passagem; como transição entre afecções, ou mesmo como ligação, bloco intensivo entre dois ou mais corpos, que produza composições e um novo comum.

Por isso compreendemos que a esquizoanálise e o esquizodrama podem operar tal como um movimento social, em sua ação de desconstruir a subjetividade capitalista para outras sensibilidades. Raspar a individualidade em caminho ao comum, à multidão. Expulsar da ira, o ressentimento, provocando uma torção para que se produza o afeto de alegria e a potencialização na constituição de um comum entre as diferenças: uma comunidade heterogênea. Ideias comuns e adequadas a um novo viver, a uma nova vida e um novo mundo. A vazão desejante produz estados afetivos, e num plano mais extenso, corporeidades.

Atualizar esses cinco movimentos nos leva ao caminho da produção de diferenciação a partir da variação dos graus de potência, da incitação dos afetos como 
Rev. Interd. em Cult. e Soc. (RICS), São Luís, v. 7, n. 2, p. 95- 113, jul./dez. 2021

ISSN eletrônico: $2447-6498$

passagens. Da produção e experimentação de intensidades e de novos territórios existenciais. Pode incitar uma transformação social que não é apenas macropolítica. A transformação dos incorporais, a transformação desejante, que é a passagem dos devires: a guerrilha das forças ativas. Por isso que principalmente em tempos de morte há que viver e desejar. Lutar e experimentar. Finalizamos com o comandante da guerrilha M-19, Jaime Bateman (1983), possivelmente outro esquizoanalista que nunca leu Deleuze, mas que sabe tanto sobre a relação afetos, potência e devires: "Hay que bailar y hay que cantar. Y no sólo a la muerte, ni cantar sólo a las derrotas. Hay que cantar a la vida, porque si se vive en función de la muerte uno ya está muerto. Las personas que viven sólo de los recuerdos están muertas, el recuerdo sin porvenir lo único que trae es tristeza, y la tristeza no genera lucha nunca, nunca”.

\section{REFERÊNCIAS}

ALLIEZ; Éric; LAZZARATO, Maurizio. Guerras e capital. São Paulo, Ubu, 2021.

BAREMBLITT, Gregorio. Introdução à esquizoanálise. Belo Horizonte, Editora Instituto Félix Guattari, 1998.

BAREMBLITT, Gregorio. Esquizodrama: 10 proposições descartáveis. Belo Horizonte, Ed. Instituto Gregorio Baremblitt, 2019.

BAREMBLITT, Gregorio. Posfácio. In ROSSI, André. Formação em esquizoanálise: pistas para uma formação transinstitucional. Curitiba, Appris, 2021. p. 151-164.

BAREMBLITT, Gregorio; AMORIM, Margarete; HUR, Domenico. Esquizodrama: teoria, métodos, técnicas - klínicas. Belo Horizonte, Editora Instituto Gregorio Baremblitt, 2020.

BATEMAN, Jaime. Bateman habla de su muerte. Semana, ago. 1983. Disponível em: https://www.semana.com/nacion/articulo/bateman-habla-de-su-muerte/3358-3/. Acesso em: 14 dez. 2021.

BICHUETTI, Jorge. Lembranças da loucura. Belo Horizonte, Instituto Félix Guattari, 1999.

BICHUETTI, Jorge. Crisevida: outras lembranças. Belo Horizonte, Instituto Félix Guattari, 2000.

DELEUZE, Gilles. Empirismo e Subjetividade: ensaio sobre a natureza humana segundo Hume [1953]. São Paulo, Ed. 34, 2001.

DELEUZE, Gilles. Nietzsche e a filosofia [1962]. Rio de Janeiro, Rio - Sociedade Cultural, 1976.

DELEUZE, Gilles. O bergsonismo [1966]. São Paulo, Ed. 34, 1999. 
Rev. Interd. em Cult. e Soc. (RICS), São Luís, v. 7, n. 2, p. 95- 113, jul./dez. 2021

ISSN eletrônico: $2447-6498$

DELEUZE, Gilles. Diferença e Repetição [1968a]. São Paulo, Brasiliense, 2006.

DELEUZE, Gilles. Lógica do sentido [1969]. São Paulo, Perspectiva, 2003.

DELEUZE, Gilles. Derrames II: Aparatos de Estado y axiomática capitalista [1979]. Buenos Aires, Cactus Editorial, 2017.

DELEUZE, Gilles. Pintura: el concepto de diagrama [1981a]. Buenos Aires, Cactus Editorial, 2007.

DELEUZE, Gilles. Cursos sobre Spinoza [1981b]. 3. ed. Fortaleza, EdUECE, 2019.

DELEUZE, Gilles. Espinosa: Filosofia Prática [1981c]. São Paulo, Escuta, 2002.

DELEUZE, Gilles. El poder: curso sobre Foucault (Tomo 2) [1986a]. Buenos Aires, Cactus editorial, 2014.

DELEUZE, Gilles. La subjetivación: curso sobre Foucault (Tomo 3) [1986b]. Buenos Aires, Cactus Editorial, 2014.

DELEUZE, Gilles. Qu'est-ce qu'un disposif? Michel Foucault philosophe. Rencontre internationale, Paris 9, v. 10, 11 jan. 1989.

DELEUZE, Gilles. Conversações [1990]. São Paulo, Ed. 34, 1992.

DELEUZE, Gilles. Dos Regímenes de locos: Textos y entrevistas (1975-1995) [2003]. Valencia, Pré-Textos, 2007.

DELEUZE, Gilles; GUATTARI, Félix. Capitalismo e Esquizofrenia: O Anti-Édipo [1972]. São Paulo, Ed. 34, 2010.

DELEUZE, Gilles; GUATTARI, Félix. Kafka: por uma literatura menor [1975]. Rio de Janeiro, Imago, 1977.

DELEUZE, Gilles; GUATTARI, Félix. Mil Platôs: Capitalismo e Esquizofrenia [1980a], vol. 1. São Paulo, Ed. 34, 1995.

DELEUZE, Gilles; GUATTARI, Félix. Mil Platôs: Capitalismo e Esquizofrenia [1980b], vol. 3. São Paulo, Ed. 34, 1996.

DELEUZE, Gilles; GUATTARI, Félix. Mil Platôs: Capitalismo e Esquizofrenia [1980c], vol. 5. São Paulo, Ed. 34, 1997.

FOUCAULT, Michel. Vigiar e Punir [1975]. Petrópolis, Vozes, 1984.

FOUCAULT, Michel. Em defesa da sociedade. São Paulo, Martins Fontes, 1999.

FUMIATO, Federico; SANTA CRUZ, Sebastián. Filosofía bal-Buceante: de la resistencia a la insistencia. Buenos Aires, Laspuertas, 2005. 
Rev. Interd. em Cult. e Soc. (RICS), São Luís, v. 7, n. 2, p. 95- 113, jul./dez. 2021

ISSN eletrônico: $2447-6498$

GONÇALVES, Mariana. Psicologia favelada: ensaios sobre a construção de uma perspectiva popular em Psicologia. Rio de Janeiro, Mórula, 2019.

GUATTARI, Félix. Cartografías Esquizoanalíticas. Buenos Aires, Manantial, [1989].

GUATTARI, Félix. As três ecologias [1989]. Campinas, Papirus, 1990.

GUATTARI, Félix. ¿Qué es la Ecosofia?: textos presentados y agenciados por Stéphane Nadaud. Buenos Aires, Cactus editorial, 2015.

HEIDEGGER, Martin. Ser e tempo, volume 1. Petrópolis, RJ, Vozes, 1995.

HUR, Domenico Uhng. Trajetórias de um pensador nômade: Gregório Baremblitt. Estudos e pesquisas em psicologia, v. 3, n. 14, p. 1021-1038, 2014. Disponível em

http://pepsic.bvsalud.org/pdf/epp/v14n3/v14n3a18.pdf. Acesso em: 14 dez. 2021.

HUR, Domenico Uhng. Corpocapital: códigos, axiomática e corpos dissidentes. Lugar Comum, n. 45, p. 232-245, 2015.

HUR, Domenico Uhng. Poder e potência em Deleuze: forças e resistência. Mnemosine, n. 12, vol. 1, p. 210-232, 2016. Disponível em: https://www.e-

publicacoes.uerj.br/index.php/mnemosine/article/view/41669/28938. Acesso em: 14 dez. 2021.

HUR, Domenico Uhng. Psicologia, política e esquizoanálise. Campinas, Alínea, 2018.

HUR, Domenico Uhng. 2020a. Educación como potencia en tiempos de neoliberalismo y fundamentalismos. Saberes y prácticas - Revista de Filosofía y educación, v. 5, n. 2, p. 112, 2020a. Disponível em:

https://revistas.uncu.edu.ar/ojs/index.php/saberesypracticas/article/view/3171/2709. Acesso em: 14 dez. 2021.

HUR, Domenico Uhng. Desejo e política em Deleuze: máquinas codificadora, neoliberal, neofascista e esquizodramática. POLIÉTICA. Revista de Ética e Filosofia Política, vol. 8, n. 2, p. 173-202, 2020b. Disponível em:

<https://revistas.pucsp.br/index.php/PoliEtica/article/view/50130/34280.

HUR, Domenico Uhng. Discursos sobre a retórica governamental de Bolsonaro: louco, genocida, necroliberal ou cortina de fumaça? Lugar Comum, n. 61, no prelo.

HUR, Domenico Uhng; COUTO, Maria Luiza B. S. Ocupações na cidade: políticas da multidão na produção do comum. Revista Psicologia política, vol. 19, n. 45, p. 261-274, 2019. Disponível em: http://pepsic.bvsalud.org/pdf/rpp/v19n45/v19n45a09.pdf. Acesso em: 14 dez. 2021.

KOPENAWA, Davi. A queda do céu: palavras de um xamã yanomami, São Paulo, Companhia das Letras, 2015.

KRENAK, Ailton. Ideias para adiar o fim do mundo. São Paulo, Companhia das Letras, 2019. 
Rev. Interd. em Cult. e Soc. (RICS), São Luís, v. 7, n. 2, p. 95- 113, jul./dez. 2021 ISSN eletrônico: 2447-6498

LIMA, Wlad. O teatro ao alcance do tato. Belém, UFPA, 2014.

MASSUMI, Brian. A user's guide to Capitalism and Schizophrenia. Massachusetts: The MIT Press, 1992.

MBEMBE, Achille. Necropolítica. 3. ed. São Paulo, [s.n.], 2018.

RODRIGUES, Heliana de B. C. Ensaios sobre Michel Foucault no Brasil: presença, efeitos, ressonâncias. Rio de Janeiro, Lamparina, 2016.

ROLNIK, Suely. Cartografia Sentimental. São Paulo, Hucitec, 1989.

ROLNIK, Suely. Psicologia: subjetividade, ética e cultura. São Paulo, Hucitec, 1997. (Saúdeloucura, 6: Subjetividade). 